DICIEMBRE 2014

\title{
MANDATO RESOCIALIZADOR DE LAS PENAS PRIVATIVAS DE LIBERTAD Y PERMISOS DE SALIDA PENITENCIARIOS. ${ }^{1}$
}

\author{
Isabel CASANOVA AGUILAR.
}

\section{Profesora Titular de Derecho Constitucional}

\section{Universidad de Murcia}

\begin{abstract}
RESUMEN: El art. 25.2 CE contempla la orientación de las penas privativas de libertad hacia la reeducación y reinserción social, otorgando con ello relevancia constitucional a una serie de cuestiones relacionadas con el fundamento y los límites del ejercicio del ius puniendi del Estado. El presente trabajo se propone, en primer lugar, realizar una aproximación general a la problemática que plantea el fin reeducador e integrador de las penas privativas de libertad en su proyección sobre las distintas fases del ciclo penal (su acción constrictora del poder del Estado). Así como, en segundo lugar, analizar el significado de los permisos de salida previstos por la legislación penitenciaria para satisfacer el mandato constitucional de resocialización del penado.
\end{abstract}

PALABRAS CLAVE: fines de las penas privativas de libertad, reclusión y reinserción social, clasificación de los penados, sistema punitivo, régimen de vida penitenciario, permisos de salida tercer grado penitenciario, libertad condicional.

ABSTRACT: Article 25.2 of the Spanish Constitution of 1978 prescribes the guidance of the imprisonment penalties towards the rehabilitation and social reintegration, conferring therefore constitutional relevance to the foundations and limits of the exercise of "ius puniendi" (right to punish) by the State. First of all this essay aims to offer a general approach to the issues concerning the rehabilitation and reintegration order of the imprisonment penalties in the context of the limiting action of the State power during the complete punishment process. As well as analyze the meaning of the exit furloughs established by the penitentiary legislation to satisfy the constitutional mandate of reintegration of the punished.

KEYWORDS: Order of the imprisonment penalties, reclusion and social reintegration, punished rating, punishing system, penitentiary life regime, exit furloughs, penitentiary Third grade, probation.

\footnotetext{
${ }^{1}$ El presente artículo ha sido realizado en el marco del Proyecto de investigación, financiado por el Ministerio de Ciencia e Innovación, DER2012 35860 "Variables para una moderna política criminal superadora de la contradicción expansionismo-reduccionismo de la pena de prisión".
} 


\section{INDICE}

I. Significado y alcance del objetivo resocializador de las penas privativas de libertad contenido en el art. 25.2 CE, según doctrina del Tribunal Constitucional.

1. La reeducación y la reinserción social, ¿derecho fundamental de los internos?

2. La cláusula constitucional de reinserción social del penado como parámetro de la constitucionalidad de las leyes penales: reeducación y reinserción social y sistema punitivo

3. La cláusula constitucional de reinserción social del penado en su proyección sobre el sistema penitenciario: resocialización del interno y régimen de vida penitenciario.

II. Especial consideración de los permisos de salida penitenciarios como instrumento resocializador de los internos.

1. Los permisos de salida penitenciarios en el sistema español: modalidades y requisitos para su otorgamiento.

2. Sobre la posibilidad de considerar los permisos de salida penitenciarios como un derecho de los internos frente a la Administración Penitenciaria.

3. La denegación de los permisos penitenciarios por la autoridad penitenciaria: peligrosidad social del reo frente a seguridad colectiva.

III. Conclusiones. 
I. Significado y alcance del objetivo resocializador de las penas privativas de libertad contenido en el art. 25.2 CE, según doctrina del Tribunal Constitucional.

El artículo 25.2 de la C.E establece que "las penas privativas de libertad estarán orientadas hacia la reeducación y reinserción social". Con esta afirmación nuestro texto constitucional evita otorgar a la pena privativa de libertad una función exclusivamente retributiva, más propia de otras épocas, para asignarle una función integradora o rehabilitadora con todas las consecuencias que ello comporta a lo largo de las distintas fases o etapas del ejercicio del "ius puniendi" del Estado ${ }^{2}$. De esta forma, la Constitución abre una serie de interrogantes que intentan dar respuesta a la forma de proyectarse dicha pretensión resocializadora tanto en el momento del establecimiento de la sanción penal privativa de libertad, como en el de su imposición a un caso concreto, o en el de su ejecución penitenciaria. Así pues, nos podríamos interrogar, en primer lugar, acerca de la capacidad del art. 25.2 C.E para operar como instrumento delimitador o constrictor de la sanción penal en el momento de ser establecida por el legislador. O, incluso, plantearnos si podemos encontrar en él una habilitación para sustituir las penas privativas de libertad, de carácter indudablemente desocializador, por otras medidas más acordes al objetivo integrador del penado constitucionalmente prescrito. O, también, podríamos cuestionarnos la procedencia o improcedencia de imponer una pena privativa de libertad a aquellos que pese a ser autores de la conducta que lleva aparejada dicha sanción no precisan ser "reeducados o "reinsertados". Y, por último, podríamos, igualmente, intentar esclarecer cuales son las obligaciones del Estado para hacer realidad en el transcurso de la ejecución de la condena ese objetivo resocializador señalado constitucionalmente.

1. La reeducación y la reinserción social, ¿derecho fundamental de los internos?

Tal y como hemos apuntado anteriormente la cláusula contenida en el art. 25.2 presenta dificultades de diversa índole a la hora de determinar su significado dada la

\footnotetext{
2 Se trataría como acertadamente señala Córdoba Roda (1980, pág. 131) de sustituir la "pena castigo" por el "tratamiento de resocialización".
} 
envergadura de las cuestiones que suscita. En primer lugar, es necesario que nos detengamos en analizar si dicha prescripción es o no portadora de un derecho subjetivo del penado a la reinserción capaz de habilitarle para exigir su eficacia en amparo constitucional ya que su reconocimiento habría tenido lugar en el ámbito de la Sección Primera del Capítulo II del Título I, esto es, en el ámbito de los derechos susceptibles de protección en amparo constitucional.

Su hipotética condición generadora de un derecho subjetivo en el interno no está exenta de consecuencias en orden a la eficacia del cumplimiento de las penas privativas de libertad fundamentalmente en relación con la posibilidad de sustentar la inaplicación de las mismas en los casos en los que el condenado no precisara de la resocialización prevista en la norma.

Así ha ocurrido en más de una oportunidad en la que el condenado a una pena de privación de libertad ha solicitado del Tribunal Constitucional la inejecución de su condena argumentando que las penas privativas de libertad han de orientarse a la reinserción y dado que durante el tiempo transcurrido entre la comisión del hecho delictivo y la ejecución de la condena se había ya producido la reinserción del sujeto recurrente, la pena rehabilitadora sería innecesaria.

Ese fue, por ejemplo, el objeto pretendido en el caso resuelto por el TC mediante la sentencia 28/1988. El supuesto de hecho que determinó el pronunciamiento del TC fue, el de un condenado a una pena de privación de libertad por un delito cometido a causa de su drogadicción que solicitaba de la autoridad judicial que, como consecuencia de haberse sometido a un tratamiento de desintoxicación con la subsiguiente superación de la drogadicción que padecía, declarase la suspensión de la aplicación de la condena impuesta fundamentando su petición de amparo "en que el art. 25 de la Constitución entiende las penas privativas de libertad no como una medida retributiva, sino encaminada a la reeducación y reinserción del delincuente, y como en su caso esa finalidad ya se ha conseguido su ingreso en prisión vulneraría el principio constitucional". En dicha sentencia el Tribunal Constitucional no estimó la pretensión del recurrente remitiéndose a una reiterada doctrina sentada con anterioridad por el mencionado Tribunal consistente en señalar que "lo que dispone el art. 25.2 es que en la dimensión penitenciaria de la pena se siga una orientación encaminada a la 
reeducación y reinserción social, más no que a los responsables de un delito al que se anuda una privación de libertad se les condone la pena en función de la conducta observada durante el periodo de libertad provisional" (ATC 486/1985), e insistiendo en que " aunque no debe desconocerse la importancia del principio constitucional en él contenido, el art. 25.2 no confiere como tal un derecho amparable que condicione la posibilidad y la existencia misma de la pena a esa orientación” (STC 2/1987).

En la misma línea puede verse la STC 381/1993 que resuelve un recurso de amparo planteado por un condenado por un delito de robo con intimidación que alega la inconveniencia de la ejecución de la sentencia a causa de sus consecuencias perturbadoras para el penado cuya reinserción social ya se había producido en el transcurso del tiempo que media entre la comisión del hecho delictivo y la sentencia. El TC al tiempo que recuerda que los instrumentos pertinentes para lograr la inejecución de la sentencia a efectos de evitar los posibles efectos perturbadores que ésta pueda producir son el indulto y la remisión judicial de la pena, desestima el amparo al considerar que ni la reinserción ni la rehabilitación social del delincuente pueden considerarse en cada caso concreto una condición de legitimidad de la pena ${ }^{3}$.

En suma, el Tribunal Constitucional ha afirmado en constante jurisprudencia que pese a que el art. 25.2 CE se halla inserto en la sección primera del Capítulo $2^{\circ}$ del Título I que es donde se encuentra el catalogo de los derechos fundamentales y las libertades públicas, la reeducación y reinserción social no puede ser considerado un derecho fundamental del penado susceptible de ser protegido por vía de amparo sino un principio constitucional orientador de la política penal y penitenciaria del Estado. ${ }^{4}$

\footnotetext{
3 También pueden consultarse a estos efectos la STC 35/1994; ATC 15/1984 y ATC 360/1990, entre otras.

${ }^{4}$ Una opinión discrepante respecto de la posición mantenida por el Tribunal Constitucional es la suscrita por José Cid Moliné (1998) para quien “la ubicación sistemática del precepto es decisiva para considerar que el primer inciso del artículo 25.2 C.E. constituye un principio del que derivan derechos fundamentales para la persona condenada a pena privativa de libertad" ("Derecho a la reinserción social. Consideraciones a propósito de la reciente jurisprudencia constitucional en materia de permisos" Jueces para la democracia no 23 , pág. 40).
} 
En consecuencia, según dicho planteamiento jurisprudencial el objetivo de reeducación y de reinserción social que el texto constitucional asigna a las penas privativas de libertad no puede servir de justificación para no imponer una pena privativa de libertad a aquellos que pese a ser autores de la conducta que lleva aparejada dicha sanción no precisan ser "reeducados" o "reinsertados" y ello no sólo porque el art. 25.2 contenga un mandato al legislador del que no se derivan derechos subjetivos, sino también porque, como tendremos ocasión de comprobar en el epígrafe siguiente, en el mencionado precepto no se establece que la reeducación y la reinserción social sean la única finalidad legítima de las penas privativas de libertad.

2. La cláusula constitucional de reinserción social del penado como parámetro de la constitucionalidad de las leyes penales: reeducación y reinserción social y sistema punitivo.

Según doctrina del TC, si bien la prescripción contenida en el art. 25.2 CE, no es fuente, en sí misma, de derechos subjetivos a favor de los condenados a penas privativas de libertad, ni menos todavía de derechos fundamentales susceptibles de amparo constitucional, sí que puede servir de parámetro de la constitucionalidad de las leyes (STC 75/1998, FJ 2). Nos corresponde a continuación analizar el cómo esa finalidad resocializadora de las penas prevista en el art. 25.2 va a ejercer esa eficacia condicionante de la validez de las leyes penales y con qué límites va a poder hacerlo.

No han sido infrecuentes las ocasiones en las que se ha solicitado el pronunciamiento del TC para enjuiciar la constitucionalidad de determinadas sanciones penales que planteaban dificultades para satisfacer las exigencias que a las penas privativas de libertad impone el art. 25.2 C.E por impedir, a causa de su escasa duración, el tratamiento reeducador constitucionalmente previsto. Así ocurrió en los supuestos planteados ante el TC cuestionando la regularidad constitucional de ciertas sanciones previstas en el Código Penal tales como la imposición de arrestos sustitutorios por impago de multas (STC 19/1998) o la condena a la pena de arresto menor (STC 120/2000). En ambas oportunidades se dictaminó la legitimidad constitucional de las mismas en base a una consideración plural de los fines de la pena. 
El Tribunal Constitucional ha afirmado de forma reiterada que el fin de prevención especial de la pena en su dimensión resocializadora no es el único fin de las penas privativas de libertad sino que las mismas pueden cumplir otros fines ya sean de prevención general o de carácter retributivo, y, en consecuencia, no es contraria a la Constitución la imposición de penas que aunque no estén orientadas a la reeducación y reinserción social puedan responder a otras finalidades de la pena ${ }^{5}$.

Por otro lado, las penas de prisión de larga duración, también suscitan ciertos interrogantes, esta vez, no solo en relación con su compatibilidad con el principio de reinserción social consagrado en el art. 25.2 C E, sino también en razón de su eventual

\footnotetext{
${ }^{5}$ En este sentido la STC 150/1991 que resuelve la supuesta inconstitucionalidad del agravante de reincidencia contemplado en el art. 10.15 del Código Penal afirma que: "El art. 25.2 C.E. no resuelve sobre la cuestión referida al mayor o menor ajustamiento de los posibles fines de la pena al sistema de valores de la C.E ni, desde luego de entre los posibles - prevención general; prevención especial; retribución; reinserción, etc. - ha optado por una concreta función de la pena en el Derecho Penal". En consecuencia, y dado que la CE no "erige a la prevención especial como única finalidad de la pena, antes al contrario, el art.25,2 no se opone a que otros objetivos, entre ellos la prevención general, constituya, asimismo una finalidad legitima de la pena", procede a declarar que "no cabe estimar inconstitucional la agravante de reincidencia por no ajustarse a los fines constitucionales de la pena" ( FJ, 4).
}

En la misma línea, la STC 120/2000, sobre la posible inconstitucionalidad de la sanción de arresto menor prevista en el art.586 bis del Código Penal de 1973, resuelve la duda fundamentada por el órgano judicial ordinario en la inadecuación de una pena de tan corta duración para el logro del efecto resocializador requerido por el art. $25.2 \mathrm{CE}$, declarando la constitucionalidad de dicha sanción al considerar que "la pena de arresto menor en si misma considerada no imposibilita que se alcance la resocialización del autor, ni impide la consecución de otros fines igualmente legítimos de la pena al amparo de la Constitución" (FJ 4).

Y, por último, la STC 19/1988, sobre el arresto sustitutorio por impago de multas cuya constitucionalidad se cuestiona en razón de su carácter meramente expiativo dada su falta de idoneidad para cumplir los fines de reeducación y reinserción social señalados por el art. 25.2 de la CE, resuelve la cuestión manifestando la imposibilidad de "descartar por inconstitucionales a todas aquellas medidas privativas de libertad que puedan parecer inadecuadas, por su relativamente corta duración, para cumplir los fines allí impuestos a la Ley y a la Administración" y apoya dicha afirmación remitiéndose a la doctrina ya consolidada al respecto según consta en el Auto 780/1986 consistente en señalar que "si bien la norma fundamental dispone que las penas privativas de libertad y las medidas de seguridad estarán orientadas hacia la reeducación y la reinserción social, de esta declaración constitucional no se sigue ni el que tales fines reeducadores y resocializadores sean los únicos objetivos admisibles de la privación penal de la libertad ni, por lo mismo, el que se haya de considerar contraria a la Constitución la aplicación de una pena que pudiera no responder exclusivamente a dicho punto de vista" (FJ 9). 
colisión con la prohibición constitucional de someter al individuo a tratos inhumanos y degradantes (art. $15 \mathrm{CE}$ ). Se trata de una cuestión objeto de debate en nuestro país a causa de un doble motivo. En primer lugar, por la ampliación producida por la LO 7/2003, de medidas de reforma para el cumplimiento íntegro y efectivo de las penas, del tope máximo de cumplimiento de la condena de 30 a 40 años, en determinados supuestos. Y, además, por la anunciada implantación por el proyecto de reforma del Código Penal que prepara el Gobierno de la denominada prisión permanente revisable.

Para ilustrar el debate podemos recurrir a algunos pronunciamientos del TC que de forma colateral nos permitirían vaticinar cual sería la respuesta de nuestro interprete supremo de la Constitución en el supuesto de que se le planteara la cuestión de la regularidad constitucional de estas decisiones.

En relación con la posibilidad de que una sanción penal colisione con la prohibición constitucional de infligir al individuo tratos inhumanos y degradantes, el Tribunal Constitucional ha afirmado que la calificación de una pena como inhumana o degradante no depende exclusivamente de su duración sino también de las condiciones en las que tiene lugar la ejecución de la misma (STC 65/1986). El supuesto de hecho que da lugar a la sentencia que comentamos es la condena del recurrente en amparo a una pena de diecisiete años como responsable de un delito de malversación de caudales públicos, que es recurrida por el reo al considerarla lesiva del art. 15 de la CE por su carácter desproporcionado. El TC no entiende que dicha lesión se produzca en base al argumento consistente en señalar que "la calificación de una pena como inhumana o degradante depende de la ejecución de la pena y de las modalidades que ésta reviste, de forma que por su propia naturaleza la pena no acarree sufrimientos de una especial intensidad (penas inhumanas) o provoquen una humillación o sensación de envilecimiento que alcance un nivel determinado, distinto y superior al que suele llevar aparejada la simple imposición de la condena" ( FJ 4).

Y respecto a la compatibilidad con la Constitución de la denominada prisión permanente revisable, nuestro Tribunal Constitucional no ha podido pronunciarse acerca de algo que está todavía en fase de proyecto, pero si lo ha hecho respecto de la pena de 
cadena perpetua prevista en el sistema italiano y, la ha considerado compatible con las exigencias del art. 25.2 CE bajo determinadas condiciones (STC 91/2000, FJ 9) ${ }^{6}$.

La STC 91/2000 es fruto de un recurso de amparo presentado por un ciudadano italiano frente a las resoluciones judiciales españolas que declaraban la procedencia de la extradición solicitada por las autoridades de su país al objeto de satisfacer la exigencia de responsabilidad penal correspondiente a su condición de autor de un cúmulo de hechos delictivos relacionados con su pertenencia a una organización mafiosa dedicada al tráfico de estupefacientes que podían ocasionarle la imposición de una pena de reclusión perpetua. El recurrente solicita en su demanda la declaración de nulidad de las actuaciones judiciales objeto de impugnación y subsidiariamente pide que "si se concediera la extradición quede condicionada a la no imposición de una pena de prisión de carácter perpetuo" y aduce en apoyo de dicha pretensión, entre otras razones, que no supeditar la extradición al cumplimiento de la condición propuesta supone la lesión de sus derechos a no sufrir penas o tratos inhumanos o degradantes (art.15 CE) y a que las penas privativas de libertad estén orientadas a la reinserción y reeducación social (art. $25 \mathrm{CE}$ ). El Fiscal considera no atendible la supuesta lesión de los arts. 15 y 25 C.E. ya que estima que "una pena de prisión perpetua no es indiscutiblemente contraria al derecho a no sufrir tratos inhumanos, y no parece contraria al art. 25.2 CE, a tenor de la propia jurisprudencia constitucional, pues la reeducación y reinserción social son únicamente aspectos orientadores de la finalidad de las penas privativas de libertad, pero ni constituyen los únicos fines de la pena, ni el art. 25.2 CE consagra derechos fundamentales protegibles en amparo por lo que al cumplimiento de las citadas finalidades respecta, sino mandatos dirigidos a los poderes públicos a la hora de concretar la política penitenciaria en todas sus facetas". El TC en relación con la alegada vulneración del principio contenido en el art. 25.2 CE reproduce el criterio mantenido con regularidad en decisiones anteriores respecto al significado y alcance del art. 25.2 CE, añadiendo que a mayor abundamiento la resolución judicial previa al amparo, esto es, la dictada por la Audiencia Nacional "ha estimado fundadamente que la legislación penal y penitenciaria italiana, incluso en el caso de la pena de ergastolo,

\footnotetext{
${ }^{6}$ Una referencia a esta sentencia se encuentra en Consejo General del Poder Judicial "Informe sobre el Anteproyecto de ley orgánica de medidas de reforma para el cumplimiento íntegro y efectivo de las penas", pág. 7.
} 
cumple las exigencias dimanantes del art. 25.2 CE, sin que por el recurrente se hayan aportado razones que desvirtúen esta apreciación"7. Y en relación con el posible carácter degradante o inhumano de dicha pena reitera su posición mantenida con anterioridad en la STC 65/1986 consistente en mantener que el carácter inhumano o degradante de la misma no depende sólo de su duración sino también de las circunstancias en las que tiene lugar la ejecución de la misma, circunstancias que, por lo demás, a juicio del Tribunal no aparecen reflejadas en las alegaciones del recurrente ( FJ 9).

Concluido el análisis de las sentencias referenciadas podemos considerar que es doctrina constitucional consolidada que a la hora de determinar la compatibilidad constitucional de una pena, no importa tanto la duración de la misma, como que en el transcurso de su ejecución el reo pueda lograr un acortamiento del periodo de cumplimiento en caso de pronóstico favorable de reinserción.

Así las cosas y dada la escasa virtualidad atribuida a dicho principio por el Tribunal Constitucional en las fases correspondientes al establecimiento y aplicación de la pena, observamos que serán las previsiones penitenciarias existentes para el periodo de ejecución de la condena el factor determinante de la regularidad constitucional del sistema punitivo de forma que queda desplazado a ese momento o estadio del ciclo penal el alcance de la eficacia del mandato resocializador constitucionalmente prescrito.

\footnotetext{
${ }^{7}$ Debemos puntualizar para un mejor entendimiento de la sentencia que comentamos que en la sección correspondiente a los antecedentes se transcribe un breve extracto del Auto 21/1988 de la Audiencia Nacional al que la misma se refiere en el FJ 9 que es del siguiente tenor: " La Sala teniendo en consideración que el reclamante es un Estado del mismo entorno jurídico-cultural, caracterizado por ostentar un sistema jurídico sumamente perfeccionado y respetuoso con las libertades públicas, que ha dado lugar a que por sus Tribunales se hayan tenido en cuenta planteamientos semejantes a los aquí indicados......estima que no es necesario pedir ninguna clase de garantías específicas y, por el contrario, considerar suficiente a los fines indicados hacer mención a la genérica garantía de que el reclamado debe gozar en el estado italiano del mismo trato que cualquier otro reo y de que en caso de ser condenado a prisión perpetua se tendrá en cuenta su evolución penitenciaria de cara a una posible excarcelación anticipada".
} 
3. La cláusula constitucional de reinserción social del penado en su proyección sobre el sistema penitenciario: resocialización del interno y régimen de vida penitenciario.

¿Cuál es el alcance de la finalidad resocializadora de las penas de prisión prescrita por el texto constitucional en su proyección sobre el sistema penitenciario?

El mandato resocializador constitucionalmente prescrito en el art. 25.2 CE, si bien no constituye, según doctrina reiterada del TC un derecho subjetivo a favor del interno que le faculte para reclamar judicialmente su eficacia, si comporta, al menos, para el legislador y la Administración Penitenciaria la obligación de observar una doble actuación, tendente, por un lado, al diseño de un régimen de cumplimiento de la pena flexible y capaz de ir adaptándose a los progresos realizados por el interno en su trayectoria hacia la rehabilitación social. Esa es la misión que cumple la clasificación penitenciaria de los internos en grados (primer grado, segundo grado, tercer grado, libertad condicional) correspondiendo a cada uno de ellos un diferente régimen de vida penitenciario (cerrado, ordinario, abierto o en libertad). Y, por otro lado, la Administración penitenciaria también debe arbitrar los mecanismos necesarios para poner a disposición de los internos los medios y tratamientos adecuados que les permitan lograr una reinserción social o lo que es lo mismo acceder a una vida en libertad sin delitos. Esa es la misión que cumple el denominado tratamiento penitenciario en cuyo seno se insertan una serie de instrumentos cuyo denominador común no es otro que operar de forma individualizada sobre los reclusos al objeto de proporcionarles la reeducación que cada uno de ellos precise para superar la conducta antisocial que en su día determinó su pérdida de libertad.

En relación con esta cuestión, no han faltado oportunidades en las que internos penitenciarios han cuestionado la legitimidad de alguna de las sanciones impuestas por el Centro al que pertenecían en razón de su inadecuación para el logro del objetivo resocializador contemplado en el texto constitucional y han solicitado, en consecuencia, su invalidación por el TC. Así ocurrió, por ejemplo, en la STC 2/1987 que resolvió el recurso de amparo de un interno solicitando la nulidad de un acuerdo de la Junta de Régimen de la prisión que le impuso una sanción de aislamiento en celda por considerar que el objetivo resocializador dispuesto en el art. $25 \mathrm{CE}$ en conexión con lo dispuesto en 
el art. 15 que garantiza el derecho a la integridad física y a no ser sometido a tortura ni a penas inhumanas y degradantes era desconocido por la referida medida sancionadora. Frente a dicha pretensión el TC reitera su posición mantenida en el Auto 486/1985 consistente en señalar que pese a la importancia de dicho precepto constitucional que debe orientar toda la política penitenciaria del Estado "el artículo 25.2 no confiere como tal un derecho amparable que condicione la posibilidad y la existencia misma de la pena a esa orientación" al tiempo que considera insuficientemente demostrado por el recurrente "en qué medida la corrección impuesta no podría contribuir en alguna medida a esa finalidad" (FJ 2).

Desde un punto de vista constitucional, el régimen de vida penitenciario que más problemas plantea es el sistema cerrado correspondiente a los internos clasificados en primer grado. Y ello en razón de que el sistema de ejecución de la condena que comporta es muy restrictivo al apoyarse básicamente en el cumplimiento de la pena en aislamiento en celda y bajo fuertes medidas de vigilancia y control. Este problema fue planteado en su día ante el TC por un grupo de internos que consideraba que el régimen de vida al que se veían sometidos como penados en primer grado de tratamiento consistente en permanencia de veintidós horas solos en sus celdas, y dos horas diarias de patio también solos, sin acceso a ninguna actividad común y sin autorización para ver televisión, ni a comunicar vis a vis con persona alguna, lesionaba, entre otros, sus derechos fundamentales a no sufrir tratos inhumanos o degradantes (art. $15 \mathrm{CE}$ ) y desconocía que la pena privativa de libertad que cumplían debía orientarse hacia la reeducación y reinserción social (art. 25.2 CE). El TC mediante la STC 119/1996 rechaza las alegaciones de los recurrentes en base a una doble argumentación. En primer lugar, no comparte la afirmación relativa a la presunta lesión del art. 15 por la condición inhumana y degradante de las condiciones en las que se producía la ejecución de la condena afirmando muy sucintamente que "sólo pueden merecer tan graves calificativos los tratos que acarreen sufrimientos de una especial intensidad o provoquen una humillación o sensación de envilecimiento distinto y superior al que suele llevar aparejada la simple imposición de la condena" (FJ 2). En segundo lugar, tampoco comparte la invocación de los recurrentes a la orientación de las penas privativas de libertad hacia la reeducación y reinserción social para cuestionar el régimen de vida que se le había impuesto y aduce en su defensa que "este principio no genera un derecho 
subjetivo a que cada aspecto de la organización de la vida en prisión se rija exclusivamente por el mismo, con independencia del también fin primordial de las instituciones penitenciarias de retención y custodia de los detenidos, presos y penados que comporta garantizar y velar por la seguridad y el buen orden regimental del Centro. Este último objetivo es el que expresamente persiguen las restricciones a las que se atribuye su nula orientación hacia la reeducación y reinserción social, con patente desconocimiento de la carencia de exclusividad de este fin en la ejecución de la pena privativa de libertad" (FJ 4). En el iter argumental de esta sentencia observamos, una vez más, la decidida y reiterada opción del TC por el carácter plural de los fines de la pena no siempre compatibles entre sí ya que pueden entrar en conflicto ${ }^{8}$ como parece ocurrir en el caso que nos ocupa. Ante el conflicto apuntado el TC establece sus prioridades y realiza su opción en el supuesto que se cuestiona, de forma que, no solo mantiene, como venía siendo habitual, que el fin de prevención especial en su versión integradora no ostenta el régimen de exclusividad, sino también que en el caso referido ha de ceder ante otras exigencias de carácter retributivo y de prevención general, así como ante determinados aspectos inocuizadores de prevención especial, capaces, como da a entender en el transcurso de la argumentación, de neutralizar al fin resocializador.

Y también han dado lugar a frecuentes debates doctrinales las modificaciones introducidas por la ley 7/2003 de Medidas de Reforma para el cumplimiento íntegro y efectivo de las penas, siendo cuestionada su constitucionalidad fundamentalmente en los aspectos relativos a la introducción del denominado "periodo de seguridad" con la subsiguiente limitación de la posibilidad de clasificación en tercer grado y en libertad condicional, así como en lo concerniente a las dificultades añadidas para la concesión de permisos de salida y de beneficios penitenciarios a los autores de determinados tipos de delitos (delitos castigados con una pena superior a cinco años y muy especialmente delitos de terrorismo o delitos cometidos en el seno de organizaciones criminales). La tacha de inconstitucionalidad que se aduce por la doctrina respecto de estas medidas radica fundamentalmente en la eventualidad de que algunas de ellas pueden comportar para los penados a quienes van dirigidas la imposibilidad de realizar el objetivo

\footnotetext{
${ }^{8}$ Puede verse al respecto el interesante trabajo de Arribas López, E. (2004). "Reflexiones en torno a los fines de la pena y a los regímenes del cumplimiento de la pena de prisión”. Revista del Poder Judicial (núm. 77, págs. 63-69).
} 
resocializador contemplado en el art. 25.2 de la $\mathrm{CE}$ al convertir en una quimera el acceso de los mismos a los instrumentos penitenciarios (permisos de salida, beneficios penitenciarios, tercer grado de tratamiento y libertad condicional), previstos para su consecución. $^{9}$

II. Especial consideración de los permisos de salida penitenciarios como instrumento resocializador de los internos.

Los permisos de salida son junto a la clasificación en tercer grado y la libertad condicional instrumentos jurídicos de capital importancia para la satisfacción del mandato constitucional orientador de las penas hacia la reeducación y reinserción social. El propio TC ha apuntado esta dimensión de los permisos penitenciarios en una de sus sentencias al afirmar que "la posibilidad de conceder permisos de salida se conecta con una de las finalidades esenciales de la pena privativa de libertad, la reeducación y reinserción social (art. 25.2 de la Constitución) y se integra en el sistema progresivo formando parte del tratamiento" (STC 112/1996, FJ, 4).

1. Los permisos de salida penitenciarios en el sistema español: modalidades y requisitos para su otorgamiento.

La LOGP prevé la existencia de dos tipos de permisos: los denominados extraordinarios (art.47.1) apoyados en razones familiares y humanitarias, y los ordinarios (art. 47.2) que a diferencia de los anteriores responden al mandato rehabilitador del penado contenido en el art. 25.2 CE ya que como señala el Reglamento

\footnotetext{
${ }^{9}$ Para un análisis exhaustivo de esta cuestión puede verse entre otros: Juanatey Dorado, C (2004). "Ley de Medidas de Reforma para el cumplimiento íntegro y efectivo de las penas y los principios constitucionales del Derecho Penal". Revista de Derecho Penal, Procesal y Penitenciario, (núm. 9, pág.12); y González Pastor, C (2003). “Análisis de la Ley Orgánica 7/2003, de 30 de Junio, de medidas de reforma para el cumplimiento íntegro y efectivo de las penas. Examen de su constitucionalidad". Actualidad Penal (núm. 40, págs. 1009-1028).
} 
Penitenciario su objetivo no es otro que preparar a los internos para la vida en libertad. Por esta razón limitaremos nuestro estudio a estos últimos.

Ahora bien, junto a esa importante función resocializadora que sin lugar a duda cumplen los permisos de salida penitenciarios, hemos de reparar que, también presentan ciertos inconvenientes ya que al constituir una vía fácil para eludir la custodia pueden entrar en conflicto con otros bienes o principios tales como el aseguramiento del cumplimiento de la condena, el interés de la sociedad por su seguridad, la necesidad de salvaguardar una vida ordenada en prisión, etc. Los permisos de salida son siempre objeto de polémica dada la alarma social que se produce cuando los internos aprovechan el disfrute de un permiso para fugarse o cometer nuevos delitos. En dichas ocasiones no sólo se frustra la finalidad preventiva especial integradora de la pena privativa de libertad sino también se producen otros efectos colaterales respecto de los demás fines de las penas privativas de libertad ya que se pierde la confianza en la justicia y los efectos intimidantes de la condena pierden intensidad. Por ello, la concesión de los permisos se halla sometida a unos requisitos y a un procedimiento complejo ${ }^{10}$ tendentes todos ellos a minimizar los riesgos apuntados.

Los artículos 47 y 48 de la Ley General Penitenciaria regulan la concesión de los permisos de salida. El art 47 LOGP exige para poder acceder a permisos ordinarios de salida los tres requisitos siguientes: estar clasificado en segundo o tercer grado, tener cumplida la cuarta parte de la condena y no tener mala conducta. Y el art. 156.1 del Reglamento Penitenciario permite denegar los permisos cuando "por la peculiar trayectoria delictiva, la personalidad anómala del interno, o por la existencia de variables cualitativas desfavorables, resulte probable el quebrantamiento de la condena, la comisión de nuevos delitos o una repercusión negativa de la salida sobre el interno".

Así las cosas, observamos que el otorgamiento del permiso no sólo depende del cumplimiento de los requisitos objetivos previstos en la ley, sino también de las concretas circunstancias concurrentes en el solicitante que puedan aconsejar la denegación del mismo y cuya apreciación corresponde a las autoridades penitenciarias y

\footnotetext{
10 Para un análisis más exhaustivo del mismo véase Fernández Arévalo, L. y Nistal Burón, J. (2012).

“Manual de Derecho Penitenciario”. Navarra: Aranzadi, págs. 631-658.
} 
a los órganos judiciales encargados de la fiscalización de estas decisiones. Es más, el propio TC ha señalado algunos de los factores que pueden ser tenidos en cuenta para hacer esa valoración de riesgos y fundamentar la denegación del permiso de salida. Entre ellos se encuentran: "el deficiente medio social en el que ha de integrarse el interno, la falta de apoyo familiar o económico, la falta de enraizamiento en España, anteriores quebrantamientos de condena o la persistencia de los factores que influyeron en la comisión del delito" (STC 112/1996, FJ 4).

En cuanto al procedimiento establecido para la concesión de permisos de salida, hemos de señalar que la solicitud de permiso presentada por el interno ha de ser informada preceptivamente por el Equipo Técnico (art. 160 RP) que no sólo comprobará la concurrencia de los requisitos objetivos requeridos por la ley para el disfrute del permiso, sino también valorará las circunstancias peculiares del solicitante a efectos de poder determinar el buen uso del mismo, debiendo emitir informe desfavorable cuando concurran las circunstancias enumeradas en el art. 156 RP. Y a la vista de dicho informe, la Junta de Tratamiento acordará la concesión o denegación del permiso solicitado que deberá ser aprobado, en caso de acuerdo favorable de la Junta, por el Juez de Vigilancia Penitenciaria o por el Centro Directivo, según se trate de internos clasificados en segundo o tercer grado de tratamiento. El interno disconforme con las decisiones denegatorias de los permisos puede ejercer las acciones correspondientes de forma que tanto el acuerdo denegatorio del permiso adoptado por la Junta de Tratamiento como la no autorización del mismo por el Centro Directivo respecto de los clasificados en tercer grado, son recurribles ante el Juez de Vigilancia Penitenciaria. Las resoluciones del Juez de Vigilancia Penitenciaria son susceptibles de apelación ante la Audiencia Provincial del lugar donde se encuentre el Centro Penitenciario, una vez presentado previamente el recurso de reforma ante aquel, quedando de este modo expedita la vía de amparo ante el TC en los supuestos en que así proceda y, en su caso, ante el Tribunal Europeo de Derechos Humanos cuando el interno considere que la denegación del permiso ha violado su derecho a la libertad.

Por lo demás, los permisos ordinarios de salida plantean básicamente dos interrogantes que analizaremos en los epígrafes siguientes, Por un lado, la cuestión relativa a si dicho instrumento rehabilitador constituye o no un derecho fundamental de 
los reclusos frente a la Administración Penitenciaria capaz de forzar al legislador penitenciario a que si quiere limitarlo tenga que cumplir con los requisitos exigidos por el TC para cualquier acción restrictiva de un derecho fundamental, esto es. la satisfacción del denominado test de la proporcionalidad que, como es de sobra conocido comprende un triple juicio: el juicio de idoneidad o de capacidad de la medida adoptada para lograr la finalidad perseguida; el juicio de necesidad o de inexistencia de otra medida menos gravosa para el derecho que se limita y capaz de producir el mismo objetivo; y, el juicio de proporcionalidad en sentido estricto o de ponderación de perjuicios y de beneficios de forma que aquellos no superen a éstos. Y, por otro, la delimitación de cuál es el margen de discrecionalidad que posee la Administración Penitenciaria para una denegación legítima de un permiso de salida.

2. Sobre la posibilidad de considerar los permisos de salida penitenciarios como un derecho de los internos frente a la Administración Penitenciaria.

Delimitar la naturaleza jurídica de los permisos ordinarios de salida no es tarea fácil ya que no existe unanimidad al respecto. Son muchas y muy variadas las opiniones existentes sobre esta cuestión que van desde la consideración de los mismos como recompensa hasta la defensa de su condición de derecho subjetivo del interno pasando por su consideración de elementos esenciales del tratamiento penitenciario de reeducación y de reinserción social que de forma individualizada se establece para cada uno de los internos.

En esa disputa ha terciado el TC afirmando en una de sus sentencias que si bien resulta indudable su conexión con la finalidad constitucional de la reeducación y reinserción contemplada en el art. 25.2, "la simple congruencia de la institución de los permisos penitenciarios de salida con el mandato constitucional establecido en el art. 25.2 CE. no es suficiente para conferirles la categoría de derecho subjetivo, ni menos aún de derecho fundamental" (STC 75/1998, FJ 2) ${ }^{11}$. Ahora bien, tras esta afirmación añade "pero que este principio constitucional no constituya un derecho fundamental no

\footnotetext{
${ }^{11}$ Previamente la STC 81/1997, FJ 3 B se había pronunciado en términos idénticos.
} 
significa que pueda desconocerse en la aplicación de las leyes, y menos aún cuando el legislador ha establecido, cumpliendo el mandato de la Constitución, diversos mecanismos e instituciones en la legislación penitenciaria precisamente dirigidos y dirigidas a garantizar dicha orientación resocializadora, o al menos, no desociolizadora precisamente facilitando la preparación de la vida en libertad a lo largo del cumplimiento de la condena" (STC 112/1996, FJ 4) ${ }^{12}$. Y llega, incluso a reconocer la posible existencia de un interés legitimo de los reclusos en la obtención del controvertido permiso penitenciario cuando en otra de sus sentencias afirma que "la existencia de un derecho subjetivo a la obtención de tales permisos, y los requisitos y condiciones de su disfrute, dependen, pues, ante todo, de los términos en que dicha institución está regulada en la legislación ordinaria. A este respecto, aunque tanto la L.O.G.P. como el Reglamento Penitenciario vigente se abstienen de calificarlo expresamente como un derecho subjetivo, parece claro que, debido a su propia previsión legal, a los internos les asiste, al menos, un interés legítimo en la obtención de dichos permisos, siempre que en ellos concurran los requisitos y demás circunstancias a que supedita su concesión" (STC 81/1997, FJ 3 C).

Así pues, el disfrute de los permisos penitenciarios es una cuestión de legalidad ordinaria que será la que determine las condiciones y los requisitos requeridos para su obtención, derivando su relevancia constitucional de la posible incidencia que la denegación de aquellos puede tener en determinados derechos y principios constitucionales consagrados en los arts. 17.1 y 25.2 C.E y, más concretamente, de la posible lesión que la denegación de un permiso pueda producir en el derecho a la tutela judicial del recurrente a causa de su insuficiente o inadecuada motivación. Pero esa es una cuestión sobre la que tendremos ocasión de insistir más adelante.

Tan sólo nos resta por plantearnos la siguiente cuestión: si los permisos de salida no constituyen un derecho de los internos frente a la Administración Penitenciaria, ¿significa ello acaso que la Administración Penitenciaria va a poder disponer discrecionalmente de ese instrumento resocializador?

${ }^{12}$ En esta misma línea pueden verse las STC 81/1997; 137/2000 y 23/2006. 
3. La denegación de los permisos penitenciarios por la autoridad penitenciaria: peligrosidad social del reo frente a seguridad colectiva.

El margen de discrecionalidad de que dispone la Administración penitenciaria a la hora de resolver las solicitudes de permisos de salida solicitados por los internos es otra de las cuestiones que plantea el tema objeto de nuestro estudio.

Como punto de partida podemos considerar que la Administración Penitenciaria goza aparentemente de cierto margen de discrecionalidad a la hora de otorgar un permiso ordinario de salida en función de que como hemos afirmado en reiteradas ocasiones "el disfrute de los permisos no es un derecho incondicionado del interno puesto que en su concesión interviene la ponderación de otra serie de circunstancias objetivas y subjetivas para impedir que la medida se vea frustrada en sus objetivos" (STC 81/1997, FJ 5). Pero el margen de que dispone es muy relativo por dos razones. En primer lugar, porque la propia ley delimita cuáles son esos elementos subjetivos que hay que tener en cuenta para el otorgamiento del permiso (art. 156.1 RP) y, en segundo lugar, porque en la apreciación de los mismos, la autoridad administrativa no actúa en solitario sino que se ve constreñida, no solo por la existencia de ciertos instrumentos y mecanismos intervinientes en la aportación de los datos necesarios al respecto, sino también por el control verificado por las instancias jurisdiccionales correspondientes ${ }^{13}$.

La cuestión de los permisos de salida penitenciarios ha sido una de las que ha provocado mayor número de pronunciamientos del Tribunal Constitucional a causa del elevado número de recursos presentados por los internos cuestionando la legitimidad de las denegaciones de los permisos solicitados en razón de su posible incompatibilidad con el fin resocializador de las penas (art. 25.2 C.E), así como por la hipotética

\footnotetext{
${ }^{13}$ Recuérdese que en el transcurso del procedimiento para la concesión de los permisos intervendrán, no sólo, el Equipo Técnico que, tras la evaluación de los motivos denegatorios a través de la TVR (Tabla de Valores de Riesgo), informará la concesión, sino también, la Junta de Tratamiento, que a la vista del informe preceptivo pero no vinculante del equipo técnico, acordará su concesión; correspondiendo al Centro Directivo o al juzgado de Vigilancia Penitenciaria la aprobación de su otorgamiento. Decisiones que, por lo demás, son todas ellas recurribles ante el Juez de Vigilancia Penitenciaria o ante la Audiencia Provincial del lugar donde se encuentre ubicado el centro penitenciario y, en su caso, ante el Tribunal Constitucional mediante el recurso de amparo.
} 
vulneración de ciertos derechos tales como el derecho a la igualdad en la aplicación de la ley (art.14) ${ }^{14}$, el derecho a la libertad personal (art. 17.1) o el derecho a la tutela judicial efectiva a causa de la insuficiente motivación de la resolución que lo deniega (art. 24).

Como vamos a comprobar a continuación, pese a la pluralidad de derechos invocados por los internos para fundamentar su recurso de amparo frente a las resoluciones administrativas y judiciales denegatorias de los permisos, el Tribunal Constitucional ha ido perfilando al respecto una doctrina en cierto modo ambigua, porque al tiempo que afirma expresamente que el trasfondo constitucional de los permisos de salida deriva de la posible afectación que las denegaciones de los mismos puede producir en "algún derecho fundamental sustantivo del interno derivable en particular de los arts. 17.1 y 25.2" (STC 299/2005 FJ 3, entre otras), cuando llega el momento de pronunciarse sobre ello, niega contundentemente que las lesiones en los derechos a la libertad personal y a la orientación de las penas a la reeducación y reinserción social puedan producirse a causa de que el interno vea frustrada su solicitud de permiso. En el primer supuesto, porque considera que no puede lesionarse un derecho del que ya se ha visto privado el interno mediante la imposición de una sentencia penal condenatoria a privación de libertad ${ }^{15}$. Y en el segundo supuesto,

\footnotetext{
${ }^{14}$ El Tribunal Constitucional, en muchas ocasiones, no estimará los recursos de amparo frente a las denegaciones de permisos apoyados en la violación del principio de igualdad porque, en la mayor parte de las veces, las alegaciones realizadas por los internos para fundamentar dicha lesión van a tener un carácter genérico ya que no aportan el término de comparación necesario para la realización del juicio de igualdad. Véase por ejemplo la STC 137/2000, FJ 1; STC 2/1997 FJ2; STC 81/1997, FJ2; STC 112/1996 FJ 1.

${ }^{15}$ Son varias las sentencias que se manifiestan en este sentido. Así la STC 167/2003 se expresa en los siguientes términos: "Al analizar la incidencia de los permisos de salida sobre el derecho a la libertad personal de los penados y la exigencia de motivación de los mismos, este Tribunal ha partido de la consideración de que las resoluciones que sobre permisos de salida se dicten en aplicación de la ley orgánica general penitenciaria y su Reglamento afectan pero nunca pueden vulnerar el derecho fundamental a la libertad personal de los internos pues la privación de ésta se ha producido por un título legítimo previo que es la imposición de una sentencia penal condenatoria a privación de libertad. A partir de dicha premisa hemos reconocido que, puesto que la concesión o denegación de permisos penitenciarios de salida sí afectan a la libertad personal, la motivación exigible para tal afectación ha de ser especialmente rigurosa de manera que el control de este Tribunal se extiende en estos casos a valorar si la motivación es concordante con los supuestos en que la Constitución española permite la afectación del valor superior libertad y por ello reconducible a los supuestos constitucionalmente lícitos
} 
porque afirma insistentemente que "art. 25.2 C.E, en cuanto alude a la orientación de las penas privativas de libertad hacia la reeducación y reinserción social, no contiene un derecho subjetivo, ni menos aún un derecho fundamental susceptible de protección en vía de amparo ${ }^{16}$. Y, por último, y en relación con el rechazo de la lesión del principio de igualdad en la aplicación de la ley con ocasión de las denegaciones del permiso, hemos de reseñar que en más de una oportunidad, el motivo del rechazo se debe a que al no cumplirse el requisito de la alteridad la demanda se reconduce por el propio Tribunal al derecho a la tutela judicial efectiva ante la posible arbitrariedad producida al ser el recurrente tratado de forma dispar por el mismo órgano judicial ${ }^{17}$.

En consecuencia, el TC solo repara en la repercusión que puedan tener los permisos de salida sobre los arts. 17.1 y 25.2 de la CE para ubicar el objeto de impugnación del recurso de amparo en la violación del derecho a la tutela judicial efectiva del interno a causa de la insuficiente motivación de la resolución denegatoria del permiso; motivación que precisamente y a causa de la afectación de los valores constitucionales en juego (los arts. 17 y 25.2 C.E), ha de ser, en palabras del TC, “especialmente rigurosa" ${ }^{18}$. Es así como, frente a las desestimaciones de los recursos fundamentados en la lesión de los derechos a la igualdad, a la libertad personal, al

de privación de los permisos de salida" ( FJ 5). Y en la misma línea se manifiestan la STC 299/2005 FJ 3; la 75/1998 FJ 3 A; y la 2/ 1997 FJ 3 A entre otras.

${ }^{16}$ STC 299/2005, FJ 2. Es necesario tener en cuenta que el art. 25.2 es el precepto invocado con mayor frecuencia como objeto de la vulneración producida por la resolución denegatoria del permiso y también es el que es rechazado por el TC en más ocasiones. Así ocurre, por ejemplo, en la STC 167/2003, FJ 6; 299/2005, FJ 2; 299/2005 FJ 2; 23/2006 FJ2; 167/2003 FJ 6; 75/1998 FJ 2; 2/1997 FJ 3 A; $157 / 2000$ FJ 3.

${ }^{17}$ En la STC 24/2005 el motivo del rechazo de la lesión del principio de igualdad en la aplicación de la ley invocada por el recurrente, se produce porque en el supuesto de hecho planteado no se cumplía el requisito de alteridad dado que el desigualmente tratado era el propio interno que en una oportunidad anterior había obtenido del mismo Tribunal una respuesta favorable a una petición idéntica a la actualmente recurrida. En la misma línea puede verse el Auto 388/2007.

${ }^{18}$ En muchas de sus sentencias el Tribunal se refiere a la necesidad de observar un "estándar de control superior" de la razonabilidad de la decisión para aquellos supuestos en los que la denegación de un permiso pueda afectar al derecho a la libertad personal o a los principios y valores derivados del art. 25.2 (STC 81/1997, FJ 4) o de "un canon de constitucionalidad más riguroso" que explique la razonabilidad de la denegación de un permiso (STC 299/2005, FJ 3) o también de "una motivación especialmente rigurosa" para que dicha afectación sea posible (STC 167/2003, FJ 5). 
controvertido derecho a la reinserción social etc., en alguna oportunidad, el interno ha logrado su propósito invalidante de la resolución judicial impugnada mediante sentencia estimatoria del TC, en las no muy frecuentes ocasiones en las que el mencionado órgano jurisdiccional, aplicando ese canon reforzado de constitucionalidad, antes referido, sobre la motivación de las resoluciones impugnadas ha considerado que éstas adolecían de falta de motivación suficiente, vulnerando, en consecuencia, el derecho a la tutela judicial efectiva del recurrente (art. 24.1 C.E), en relación con su derecho a la libertad (art. $17 \mathrm{CE}$ ) y los principios constitucionales establecidos en el art. $25 \mathrm{CE}^{19}$. Es más, en alguna oportunidad ha sido el propio Tribunal el que, haciendo uso de las facultades que le atribuye el art. 85 de la LOTC, sugiere de oficio al recurrente fundamentar el recurso de amparo en la presunta lesión de su derecho a la tutela judicial efectiva por falta de motivación suficiente y no arbitraria (art. 24.1 CE) de la resolución denegatoria ${ }^{20}$.

Pero ¿cuáles son los requerimientos o exigencias de ese control especialmente riguroso y cuáles son las modulaciones que comporta respecto del estándar general de control? Son varias las sentencias que arrojan luz en este terreno. Así la STC 75/ 1998 señala que el estándar general del control de la tutela judicial efectiva "sufre una modulación en el ámbito de los permisos de salida, por cuanto la situación de prisión sobre la que actúa supone una radical exclusión del valor superior de la libertad, por lo que en esta materia es exigible una motivación concordante con los supuestos en los que la Constitución permite la afectación de dicho valor superior" y añade que "para respetar el contenido del derecho a la tutela judicial efectiva es preciso que la resolución que deniegue la concesión de un permiso de salida se funde en criterios conformes con los principios legales y constitucionales a los que está orientada la institución” ( FJ 3B

\footnotetext{
${ }^{19}$ Al menos en estas tres sentencias ( STC 23/2006; STC 24/2005 y 112/1996) la estimación del amparo se produjo como consecuencia de que el TC consideró que se había violado el derecho a la tutela judicial efectiva del recurrente como consecuencia de la aplicación de ese canon de constitucionalidad más riguroso que considera necesario aplicar cuando están en juego determinados valores constitucionales relacionados con el derecho a la libertad y los principios constitucionales establecidos en el artículo 25.2CE.

${ }^{20}$ Así ocurrió en la STC 112/1996 tal y como se indica en el FJ 1; en esta oportunidad la alegación del art. 24.1 CE determinó la estimación del recurso de amparo. Otras ocasiones en las que también tuvo lugar la aludida sugerencia del TC fueron los supuestos planteados en las STC 81/1997 y 2/1997 pero en estas oportunidades no se produjo la estimación del amparo.
} 
in fine). Y, más tarde, la STC 24/ 2005 precisaría aún más esta idea cuando afirma que "son ya muchas las ocasiones en las que nuestra jurisprudencia se ha ocupado de determinar cuándo una resolución judicial denegatoria de un permiso de salida a un preso constituye un ejercicio efectivo de tutela judicial. El canon de constitucionalidad resultante es mas riguroso que el genérico que repara solo en si la resolución impugnada es arbitraria, manifiestamente irrazonable o fruto de un error patente. La razón estriba en que...... no cabe duda de que en las decisiones en torno a los permisos de salida está en juego el valor superior de la libertad, pues de la concesión de los mismos va a depender que el preso disfrute de una cierta situación de libertad de la que de ordinario, y con fundamento en la propia condena que así lo legitima, carece........Este trasfondo constitucional, y con ello no solo la obvia necesidad social de que la pena no se quebrante, ha de formar parte de la ponderación judicial que informe la decisión sobre el permiso solicitado. No es pues constitucionalmente suficiente que el Auto en cuestión se apoye sin más en el Reglamento penitenciario -y esté en tal sentido fundado en Derecho- y que así lo exprese - y esté en tal sentido motivado-, sino que es imprescindible que tome en consideración los valores constitucionales en juego y que de un modo u otro exponga tal ponderación" (FJ 3).

Y ya, en el terreno de los hechos concretos, el TC en más de una de sus sentencias ha entrado a pronunciarse acerca de la "razonabilidad" de algunos de los motivos más frecuentemente aducidos por la Administración Penitenciaria para proceder a denegar los permisos solicitados tales como la larga condena o la lejanía para el cumplimiento de la condena; la drogadicción y la reincidencia del penado; la gravedad y la repercusión social del hecho delictivo; la ausencia de vinculación sociofamiliar significativa; la no aceptación por el interno del programa individualizado de tratamiento propuesto por el Centro Penitenciario, etc.

Así, la STC 24/2005 considera razonable que el establecimiento penitenciario deniegue el permiso por el riesgo de quebrantamiento de condena sustentado en la falta de arraigo del interno en nuestro país y en el largo tiempo que le queda aún de cumplimiento de la pena de prisión porque según se afirma en el texto "ninguno de los dos factores es ajeno a la necesaria ponderación de los intereses en juego. Por una parte, porque no cabe entender como no razonable el que la falta de arraigo pueda hacer que el 
permiso entorpezca el proceso de resocialización o pueda favorecer el quebrantamiento de la condena; por otra porque, como ya hemos señalado en otras ocasiones, tampoco resulta irrazonable la consideración de que el plazo lejano para la vuelta al pleno ejercicio de la libertad personal no es ajeno ni al riesgo de quebrantamiento ni a los fines de la institución de los permisos de salida, y en concreto a la preparación de la vida en libertad" ( FJ 4).

Y, la STC 167/ 2003, FJ 6) se pronuncia sobre la razonabilidad de apoyar la no concesión de un permiso penitenciario en la negativa del interno a aceptar un programa de tratamiento que se le había propuesto por el equipo de tratamiento del centro penitenciario al objeto de suplir las deficiencias personales que se entendía relacionadas con la actividad delictiva por la que el interno cumplía condena.

La drogodependencia no superada también es objeto de consideración por el Tribunal Constitucional como causa razonable de desestimación del permiso solicitado (STC 299/2005, FJ 4).

Por último, el motivo de la lejanía en el tiempo para el cumplimiento de la condena como posible causa legitimadora de un rechazo del permiso merece nuestra particular consideración ya que con respecto de ella se ha producido una matización o más bien un cambio de criterio por parte del Tribunal. Esta posibilidad, si bien fue inicialmente rechazada por el TC al considerarla contraria a la prescripción resocializadora pues parecía ignorar las funciones que el permiso estaba llamado a cumplir al olvidar que "a través de la clasificación y progresión en grado los penados pueden acceder a regímenes de semilibertad a cuya preparación son también funcionales los permisos" (STC 112/1996 FJ 6), fue más tarde aceptada por las STC 81/1997 y 137 /2000, entre otras, que acabaron afirmando la razonabilidad de la utilización del criterio de duración de la condena para justificar la denegación del permiso. La primera de ellas considera razonable fundamentar la resolución denegatoria del permiso en la lejanía para el cumplimiento de las tres cuartas partes de la condena por considerar que "dicha lejanía le sitúa en un momento no idóneo para la progresiva preparación para la vida en libertad conforme al propio espíritu y finalidad de los permisos ordinarios de salida dentro del contexto de la reinserción social orientador de la legislación en materia penitenciaria" (FJ 5). Y la segunda, porque "la apreciación de la fecha todavía lejana 
para acceder a la libertad condicional resulta ser la ponderación de una circunstancia que evidentemente guarda conexión con los fines de la institución” (FJ 2).

III. Conclusiones.

1. Como hemos tenido oportunidad de comprobar a lo largo del presente estudio, el Tribunal Constitucional en lo concerniente a las dos primeras fases del ciclo penal, esto es, en el momento del establecimiento de la pena privativa de libertad por el legislador penal y en el momento de la imposición de la misma por la instancia correspondiente al autor del tipo delictivo de que se trate, ha mantenido reiteradamente una actitud muy restrictiva y precautoria respecto a la eficacia jurídica de la orientación resocializadora de las penas privativas de libertad prevista en el art. 25.2 de la CE. Para ello ha utilizado un único y recurrente argumento: la orientación rehabilitadora de la pena no es un derecho del penado ni tampoco es el único fin atribuible a las penas privativas de libertad de forma que la clausula contenida en el primer inciso del art. 25.2 C.E no puede servir de excusa para no imponer dicha sanción a quien no precise ser "reeducado" o "reinsertado" así como tampoco para determinar la ilegitimidad de aquellas penas no orientadas a ese objetivo rehabilitador o incluso difícilmente compatibles con el mismo siempre que cuenten en su haber la consecución de cualquier otro fin legítimo ${ }^{21}$. En el transcurso de dicho discurso, nuestro interprete de la Constitución no ha seguido la estela del Tribunal Federal Alemán, más proclive a considerar la relevancia del principio resocializador, dotándole, incluso, del máximo nivel de eficacia al aplicarlo en la solución de

\footnotetext{
${ }^{21}$ Como acertadamente señala la doctrina esa eficacia condicionante de la validez de las leyes penales que puede ejercer el texto constitucional quedaría reducida, una vez salvaguardado el ámbito de libertad de que dispone el legislador a la hora de delimitar el sistema punitivo, a las leyes penales fundamentadas en principios o valores ajenos o incompatibles con el texto constitucional. Véase el interesante trabajo de Joaquín URÍAS MARTÍNEZ "El valor constitucional del mandato de resocialización". Revista Española de Derecho Constitucional no 63 (septiembre-diciembre de 2001) págs. 69-70.
} 
algún caso concreto que se le ha planteado pese a que en la Ley Fundamental no haya obtenido un reconocimiento expreso habiendo sido inducido de él por el propio Tribunal tras su consagración legal. ${ }^{22}$

2. Y, ya en el momento de la ejecución de la condena, que es el espacio al que queda desplazada por la jurisprudencia constitucional española la eficacia de dicho principio, vuelven a hacer acto de presencia esas reticencias y reservas iniciales ya que en coherencia con el discurso anterior, el Tribunal Constitucional, si bien considera que la previsión penitenciaria de instrumentos de rehabilitación del penado constituye una exigencia del mandato constitucional contenido en el art. 25.2 C.E, no se manifiesta proclive a considerar el acceso a esos instrumentos rehabilitadores previstos por la legislación penitenciaria - léase permisos, beneficios penitenciarios, libertad condicional - como un derecho fundamental de los internos, con lo cual la orientación rehabilitadora de las penas privativas de libertad queda en el momento de su cumplimiento degradada al nivel de la legalidad ordinaria.

3. En relación con el significado de los permisos de salida penitenciarios y las condiciones y requisitos exigidos para su denegación por la autoridad penitenciaria el Tribunal Constitucional es víctima de sus propias indecisiones y queda inmerso en las contradicciones derivadas de su reiterada doctrina mantenida al respecto ya que al tiempo que afirma que los mismos no constituyen un derecho del interno ha de construir todo un artificio con el que poder determinar la legitimidad o ilegitimidad de las denegaciones de permisos por las autoridades penitenciarias y judiciales cuando es compelido a realizar el control correspondiente. Es así como surge la doctrina del "canon de constitucionalidad más riguroso" o del "estándar de control superior" para medir la razonabilidad de la denegación de un permiso en aras de proteger el interés legítimo de los internos a la obtención de aquellos. Con ella el T.C. no quiere decir otra cosa que, dado el trasfondo constitucional de los permisos en razón de la posible afectación de otros derechos del reo a la que pueden dar lugar, la motivación que debe acompañar a las decisiones denegatorias de los

${ }^{22}$ Esta información ha sido obtenida del trabajo de Urias Martínez antes citado págs. 54-56. 


\section{Revista Internacional de \\ Doctrina y Jurisprudencia}

permisos ha de ser más rigurosa y adecuada a los requerimientos de los derechos afectados.

4. Para concluir y a modo de recapitulación final hemos de indicar que este es el estado de la cuestión que consideramos que se encuentra, en parte, motivada por la contradicción existente en la pretensión resocializadora en un ambiente desocializador como el que impera en el sistema carcelario actual; contradicción que explicaría la escasa fe en el principio que propugna la orientación de las penas privativas de libertad hacia la reeducación y reinserción social. Quizás el hallazgo de un sistema punitivo superador de la contradicción expansionismoreduccionismo de la pena de prisión podría ayudar a un cambio de esta actitud en beneficio de una sociedad a la que le interesa la prevención y la reducción de la delincuencia. 